\title{
IMPACT OF LEARNING CONTENT ON WORLD HERITAGE SITE PRESERVATION AWARENESS IN TOWN OF LUANG PRABANG, LAO PDR: APPLICATION OF PROTECTION MOTIVATION THEORY
}

\author{
Y.S. Poong, S. Yamaguchi, J. Takada \\ Department of International Development Engineering, Tokyo Institute of Technology, Japan - poong.y.aa@m.titech.ac.jp \\ Global Scientific Information and Computing Center, Tokyo Institute of Technology, Japan - yamaguchi.s.ae@m.titech.ac.jp \\ Department of International Development Engineering, Tokyo Institute of Technology, Japan - takada@ide.titech.ac.jp
}

KEY WORDS: international development, world heritage site, education, awareness, protection motivation theory

\begin{abstract}
:
This paper addresses the need to systematically design learning content to promote world heritage site preservation awareness. Based on 212 samples from a local university in Luang Prabang, Lao PDR, impact of learning content designed according to Protection Motivation Theory (PMT) is assessed through a repeated-measure t-test. Findings show that PMT-based learning content influences respondents' on threat appraisal and coping appraisal towards the preservation of world heritage site.
\end{abstract}

\section{INTRODUCTION}

Town of Luang Prabang was inscribed as the World Heritage Site in 1995 due to its harmonious blend of traditional Lao architecture and colonial building architecture in a natural landscape. As a result, the influx of tourists to the world heritage site has created new economic opportunities and introduced foreign culture to the local community. Signs of noncompliance building structures with the Safeguarding and Enhancement Plan (PSMV) have triggered an urgent call to raise awareness to protect the unique townscape (UNESCO, 2008).

The protection of world heritage site involves proper management practices and policies to ensure long-term preservation objectives to be met. The Department of World Heritage of Luang Prabang (DPL) is responsible in the government of building architectures, restoration of monuments, and raising preservation awareness among the local communities. Multiple programs have been undertaken to raise awareness through campaign by visiting each of the 29 villages. However, limited participation rate due to time and venue constraints triggers new approach to raise preservation awareness. Leveraging the advantage of high mobile phone penetration rate in Lao PDR, past study has mobile learning as a potential medium in supplementing awareness raising among the local community of Luang Prabang (Poong, Yamaguchi, \& Takada, 2013). Accordingly, there is a need to develop persuasive learning content with regard to the preservation of Luang Prabang world heritage site.

The objective of this paper is to review existing works related to persuading the public to preserve world heritage sites. This is followed by the development of learning content based on modified Protection Motivation Theory. Subsequently, this paper analyzes the impact of the learning content on preservation awareness using repeated-measure approach and conclude with recommendations that may guide developers of subsequent awareness raising contents.

\section{LITERATURE REVIEW}

\subsection{Current State of Preservation Awareness Promotion Strategy}

Efforts to create awareness for heritage site preservation are taking place all over the world. The heritage office of Mysore city in India has put forth activities, such as workshops, seminar, photo exhibitions and visit to heritage areas, for tourists as well as local communities (Shankar \& Swamy, 2013). However, lack of effort in developing effective education materials for creating awareness is identified as one of the weaknesses of the heritage conservation campaign (Shankar \& Swamy, 2013). Jimura (2011) has identified that raising local people's awareness of world heritage site of Shirakawa-go in Japan as one of the top three priorities (Jimura, 2011). However, there is insufficient insight on the mechanism to effectively promote local people's awareness towards the preservation of Shirakawa-go. In the study of balancing use and preservation in cultural heritage management, Carter and Grimwade (1997) provided extensive recommendations in the form of site management tools for management or policy decision. One of the strategic actions involves "promoting the values of the place, visit opportunities and protective behaviour" through advertisement communication (Carter \& Grimwade, 1997). Nevertheless, framework for effective promotion of protection behaviour of cultural heritage place is not provided for managers. Millar (1989) proposes conservation and tourism management of heritage attractions. While emphasizing the importance of conservation element in heritage presentation for tourists, details on effective approach to promote conservation were not reported. UNESCO has identified a holistic framework for the management of biosphere (Kuijper, 2003). Although the paper stresses the need and importance of environmental education for sustainable development, knowledge gap remains on effective communication strategy aiming to meet its development objective.

Existing studies rarely go beyond stating the importance of promoting heritage site preservation awareness. There are even less papers in the development and evaluation of materials related to the preservation of world heritage site. In addition, studies which include theoretical analysis of materials 
persuading target audience to engage in world heritage site preservation behaviours are limited. Therefore, a systematic learning content development based on solid theoretical model to promote preservation awareness is necessary.

\subsection{The General PMT Model}

The Protection Motivation Theory (PMT) is a comprehensive behaviour change model that has traditionally been used in the development and evaluation of campaign materials related to health issues (Cismaru, Lavack, Hadjistavropoulos, \& Dorsch, 2008; Rogers, 1975; Rogers, 1983). PMT is a persuasive communication theory originally derived from fear appeal. Fear appeal relies on threat to an individual's well-being that motivates him or her towards a desired action outcome (Bagozzi $\&$ Moore, 1994). Threat appeal effect on behavioral change, however, does not yield consistent results (Ruiter \& Kok, 2005). Addressing the weakness of fear appeal theory, PMT posits that protective actions are influenced by both threat and coping appraisals, as shown in Figure 1 (Rogers, 1983). Two factors determine the assessment of threat: (1) perceived severity, which refers to "the belief that the proposed threat is significant and potentially very harmful" (Nelson, Cismaru, Cismaru, \& Ono, 2011, p. 166) and (2) perceived vulnerability, "the belief that the proposed threat can have a personal and direct impact on either individuals or society" (Nelson, Cismaru, Cismaru, \& Ono, 2011, p. 166). The next coginitive process involves evaluation of coping options, which consists of two factors: (1) self-efficacy, "the belief that the audience can actually follow the specific recommendations that will diminish the threat" (Nelson, Cismaru, Cismaru, \& Ono, 2011, p. 167), and (2) response-efficacy, "the belief that the adoption of the recommendations can effectively prevent or diminish the negative effects of the threat" (Nelson, Cismaru, Cismaru, \& Ono, 2011, p. 167).

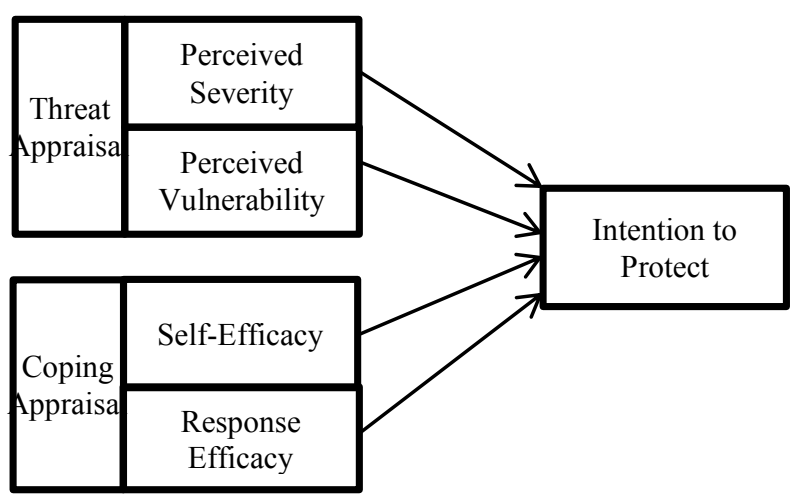

Figure 1: Protection Motivation Theory

Source: Rogers, 1983

\subsection{Application of PMT in Diverse Domains}

PMT is organized along human's cognitive process in evaluating threat and coping alternatives, and thus, is considered as a better theory than other related theories, such as the Health Belief Model (Prentice-Dunn \& Rogers, 1986). Further, PMT extends previous theories by including self-efficacy factor, which is believed as one of the most prominent improvement over past fear appeal theories (Floyd, Prentice-Dunn, \& Rogers, 2000). As a result, PMT has been applied to other fields of study including environmental topics and information security policy (Cismaru, Cismaru, Ono, \& Nelson, 2011; Markelj, 2009; Vance, Siponen, \& Pahnila, 2012). Markelj (2009) examines environmental communications using PMT and found that self-efficacy is the most employed message components in in-home energy saving advertisements. On the other hand, severity, vulnerability, and response-efficacy message components are underemployed. With regard to the application of PMT on the examination of energy saving communications, Markelj (2009, p. 122) states that PMT's "health communication-based character facilitated to bring to light few notions that might otherwise not have been detected". In addition, Floyd et. al. (2000) supports that PMT is useful not only for interventions involving individual, but also interventions involving community as well. Therefore, based on the previous reasons, the authors argue that PMT is applicable in world heritage site context due to possible negative consequences following failure of heritage site protection.

\subsection{Application of PMT in World Heritage Site}

In contrast to monument world heritage sites, town of Luang Prabang is a living heritage, in which local people live harmoniously within the unique townscape. As depicted in the previous section, proper management planning is required in the preservation of heritage site. Any actions taken in heritage site management are directly related with the local community people, which include promoting preservation awareness. Manzo and Perkins (2006, p. 336) indicate that "our thoughts, feelings, and beliefs about our local community places...impact our behaviours toward such places, thus influencing whether and how we might participate in local planning efforts". People who have low emotional connection to the place will have lower level of commitment to perform actions for the place well-being. This notion is referred as "place attachment", and is defined as "an affective bond or link between people and specific places" (Hidalgo \& Hernandez, 2001, p. 274). Therefore, including place attachment factor in this study is deemed justifiable from theoretical perspective.

\subsection{Establishment of Hypothesis}

The purpose of this investigation is to utilize a persuasive message containing threatening and coping information to test the ability of protection motivation theory, in addition to place attachment, on an individual's perception on world heritage site preservation awareness. Therefore, the null hypothesis for this study states that there are no mean differences on perception scores of perceived severity, perceived vulnerability, selfefficacy, response efficacy, place attachment, and behavioral intention between the means of pre-exposure and post-exposure of the learning content.

\section{METHODOLOGY}

\subsection{Learning Content Development}

Together with the local heritage management experts in DPL, learning content aiming to promote Luang Prabang world heritage site preservation awareness is developed. This section explains how the learning content is designed to fit into the PMT.

First, the fact that town of Luang Prabang is one of the very few world heritage sites in South East Asia is highlighted. Among the 779 heritages in the world, only 36 world heritage sites exist in South East Asia, including Luang Prabang. Town of Luang Prabang is the first world heritage site in Laos, and is the world's only place where traditional Lao buildings and European colonial buildings are built together in a townscape coexisting with beautiful nature. 
Then, the specific contents are developed referring to each factor of PMT as follows. Perceived severity is stimulated by presenting the question: "what if we do not protect Luang Prabang world heritage site?" Four possible consequences were identified: (1) possible loss of traditional heritage in the future; (2) tourists visits will fall; (3) national pride will be affected; and (4) local economic income will fall. Perceived vulnerability is stimulated by presenting the question: "how likely will Luang Prabang be listed as world heritage site in danger?" Two possibilities are identified: (1) people not following rules and regulations when building or renovating houses; and (2) lack of awareness to preserve Luang Prabang as a world heritage site. Sample pictures of illegal activities are illustrated in the learning content as well. Perception of self-efficacy is stimulated with the statement: "you can easily help to preserve Luang Prabang world heritage site". Two responses are suggested as: (1) by understanding \& knowing that it is important to preserve Luang Prabang World Heritage Site; and (2) Using Internet technologies (such as Facebook, LINE messenger application) to promote Luang Prabang heritage and culture.

The closing of the learning content comprises of statement stimulating the pride of the learner towards Luang Prabang. Localized images are included to increase familiarity. In addition, images of local people with varying facial expression depending on content are included to increase persuasiveness. This is developed based on the notion that emotion is contagious and thus face expressions are widely used in persuasive communication (Small \& Verrochi, 2009).

\subsection{Survey Questionnaire Development}

A within-subject repeated measure question survey approach was adopted to identify any difference of perceptions before and after reading the learning content. The survey questionnaire consists of 22 questions related to PMT and place attachment, one question on internet use behaviour, and finally demographic questions. Question items related to PMT and place attachment was adapted from respective literature and reworded to suit the study context.

Each PMT perception is measured by three questionnaire items. A 5-point Likert scale is employed to measure responses. Perceived severity is measured using degree of severity scale, in which scale 1 is "very much severe" and scale 5 is "not at all severe". Perceived vulnerability is measured using degree of probability, in which scale 1 is "very probable" and scale 5 is "not probable". Self-efficacy is measured using degree of confidence, in which scale 1 is "very confident" and scale 5 is "no confident at all". Response efficacy, behavioural intention to increase preservation awareness, and place attachment are measured using degree of agreement, in which scale 1 is "strongly agree" and scale 5 is "strongly disagree".

The questionnaire survey was first developed in English and was validated by native university professor. After the English review, questionnaire was sent to DPL for translation into Lao language. Translated questionnaire was then reviewed by local experts including university lecturer in Laos to determine accuracy of translation. In this stage, some sentences were reworded to increase readability. The revised questionnaire was pilot-tested with 52 students in National University of Laos to identify possible flaws in sentence meaning.

\subsection{Sampling and Questionnaire Administering Procedure}

Considering that young generation may assume important responsibilities in the future that may directly or indirectly influence the preservation of heritage site, multiple discussion sessions with DPL experts concluded that targeting young population is deemed suitable as there is a need to increase young generation sensitivity towards Luang Prabang world heritage site knowledge as well as preservation awareness. In addition, young population is believed to play potential role in influencing others, such as family members who own heritage buildings, through their ability of accessing updated information from internet and school.

Empirical data was collected from Souphanouvong University (SU) in November 2014. SU is one of the four national universities in Lao PDR and was established in the town of Luang Prabang in 2003. A total of 238 students participated in the survey. Students answered the survey questionnaire prior to reading the learning content. Then access link to the learning content was provided. Students were provided sufficient time to read the learning content carefully. Finally, students answer the survey questionnaire, which consists of similar questions answered in pre-test.

\section{RESULTS}

\subsection{Respondent's Demographic}

After discarding incomplete questionnaire, 212 responses were considered suitable for data analysis, yielding a valid response rate of $89.08 \%$. Respondents are mainly composed of male $(74.1 \%)$ than female $(20.8 \%)$. As shown in Table 4.1 , majority of the respondents is around 21 to 25 years old (57.5\%). Second year, third year, and forth year students each composed of about $30 \%$ of the sample. Respondents who access to Internet using mobile devices (mobile phones \& tablets) everyday consist of $45.3 \%$. Demographic result shows that respondents are representing a relatively technologically keen young adult population.

\subsection{Summary of Data Analysis}

Impact of learning content is measured by the degree of mean difference of the measurement items. Table 1 shows the mean differences of each measurement items before and after respondents are exposed with the learning content stimulus. Paired t-test analysis is conducted in order to evaluate whether the mean difference is statistically significance.

Mean difference of perceived severity, perceived vulnerability, self-efficacy, and behavioural intention is statistically significant. Referring to the questionnaire items as shown in Appendix, respondents rates stronger agreement on the severity on tourists visit $(\mathrm{t}=4.722, \mathrm{p}=0.000)$ and economic income $(t=3.382, p=0.001)$ after they read the learning content. Mean difference of perceived severity is calculated by averaging three severity items, as shown in bold in Table 1. Result shows that mean difference of perceived severity is statistically significant $(\mathrm{t}=4.082, \mathrm{p}=0.000)$. Next, stronger agreement on "the possibility that Luang Prabang will become world heritage site in danger" following "the ignorance of rules and regulations" ( $\mathrm{t}=4.559$, $\mathrm{p}=0.000)$ and "cutting trees without approval" ( $\mathrm{t}=3.186$, $\mathrm{p}=0.002$ ) are indicated after respondents are exposed to the learning content. Statistically significant mean difference was observed on perceived vulnerability $(\mathrm{t}=4.055, \mathrm{p}=0.000)$ as a 
consequence of reading the learning content. The learning content appears to successfully facilitate respondents' threat appraisal on the severity and vulnerability of not preserving Luang Prabang world heritage site.

Table 1. Mean differences paired t-test analysis

\begin{tabular}{|c|c|c|c|c|}
\hline & Mbe & Maf & $\mathbf{t}$ & Sig. \\
\hline \multicolumn{5}{|l|}{ Severity } \\
\hline S1 & 1.8349 & 1.5613 & 4.722 & 0.000 \\
\hline $\mathrm{S} 2$ & 1.8947 & 1.6792 & 3.382 & 0.001 \\
\hline S3 & 1.8066 & 1.6981 & 1.545 & 0.124 \\
\hline $\begin{array}{l}\text { Total } \\
\text { Average }\end{array}$ & 1.8454 & 1.6462 & 4.082 & 0.000 \\
\hline \multicolumn{5}{|c|}{ Vulnerability } \\
\hline V1 & 2.2642 & 1.9151 & 4.559 & 0.000 \\
\hline V2 & 2.2311 & 2.0094 & 3.186 & 0.002 \\
\hline V3 & 1.7877 & 1.7783 & 0.154 & 0.878 \\
\hline $\begin{array}{l}\text { Total } \\
\text { Average }\end{array}$ & 2.0943 & 1.9009 & 4.055 & 0.000 \\
\hline \multicolumn{5}{|c|}{ Self-efficacy } \\
\hline SE1 & 2.2028 & 2.0047 & 3.768 & 0.000 \\
\hline SE2 & 2.3302 & 2.0189 & 5.422 & 0.000 \\
\hline SE3 & 2.4858 & 2.1509 & 5.445 & 0.000 \\
\hline $\begin{array}{l}\text { Total } \\
\text { Average }\end{array}$ & 2.3396 & 2.0582 & 7.494 & 0.000 \\
\hline \multicolumn{5}{|l|}{$\begin{array}{l}\text { Response } \\
\text { efficacy }\end{array}$} \\
\hline RE1 & 1.6849 & 1.8019 & -2.073 & 0.039 \\
\hline RE2 & 2.0849 & 1.9575 & 2.093 & 0.038 \\
\hline RE3 & 1.7500 & 1.6934 & 0.993 & 0.322 \\
\hline $\begin{array}{l}\text { Total } \\
\text { Average }\end{array}$ & 1.8399 & 1.8176 & 0.600 & 0.549 \\
\hline \multicolumn{5}{|c|}{$\begin{array}{l}\text { Place } \\
\text { attachment }\end{array}$} \\
\hline $\mathrm{P} 1$ & 1.6085 & 1.7453 & -2.850 & 0.005 \\
\hline $\mathrm{P} 2$ & 1.9474 & 1.9387 & 0.172 & 0.864 \\
\hline $\mathrm{P} 3$ & 2.1490 & 2.0660 & 1.501 & 0.135 \\
\hline $\mathrm{P} 4$ & 1.8113 & 1.8821 & -1.355 & 0.177 \\
\hline P5 & 1.9960 & 2.0236 & -0.602 & 0.548 \\
\hline P6 & 2.0142 & 2.1166 & -1.931 & 0.055 \\
\hline P7 & 2.3491 & 2.1745 & 3.419 & 0.001 \\
\hline $\begin{array}{l}\text { Total } \\
\text { Average }\end{array}$ & 1.9814 & 1.9924 & -0.418 & 0.677 \\
\hline \multicolumn{5}{|c|}{$\begin{array}{l}\text { Behavioral } \\
\text { intention }\end{array}$} \\
\hline $\mathrm{B} 1$ & 2.2170 & 1.9528 & 4.841 & 0.000 \\
\hline $\mathrm{B} 2$ & 2.1604 & 2.0330 & 2.484 & 0.014 \\
\hline B3 & 2.0330 & 1.8832 & 2.946 & 0.004 \\
\hline $\begin{array}{l}\text { Total } \\
\text { Average }\end{array}$ & 2.1368 & 1.9563 & 4.739 & 0.000 \\
\hline
\end{tabular}

Mbe: mean before exposure to stimulus

Maf: mean after exposure to stimulus

The mean differences of all three items of self-efficacy are statistically significant. Specifically, respondents indicate stronger agreement on their confidence in understanding the importance of preserving world heritage site of Luang Prabang $(\mathrm{t}=3.768, \mathrm{p}=0.000)$, confidence in understanding the importance of following rules and regulations $(\mathrm{t}=5.422, \mathrm{p}=0.000)$, and confidence in spreading world heritage site preservation awareness $(t=5.445, p=0.000)$ after they read the learning content. As a result, the mean difference of self-efficacy is statistically significant $(t=7.494, p=0.000)$, indicating the largest change of mean difference among other PMT factors. The mean difference of understanding the importance of preserving Luang Prabang world heritage site as an effective response to preserve world heritage site is statistically significant $(\mathrm{t}=-2.073, \mathrm{p}=0.039)$, despite the fact that mean value increases from 1.6849 to 1.8019 . This implies that the degree of agreement has become weaker after respondents read the learning content. The mean difference of using Internet technologies to promote world heritage site preservation awareness is statistically significant $(\mathrm{t}=2.093$, $\mathrm{p}=0.038$ ) after respondents are exposed to the learning content. The mean difference of response efficacy, however, is not statistically significant $(t=0.600, p=0.549)$. Result indicates that learning content facilitates self-efficacy factor of coping appraisal, but not response-efficacy factor.

The mean difference of positive feelings towards Luang Prabang is statistically significant $(\mathrm{t}=-2.850, \mathrm{p}=0.005)$, despite the fact that the degree of agreement is weakened (mean before $=1.6085$, mean after $=1.7453$ ) after respondents read the learning content. However, the mean difference of the perception that living in Luang Prabang has higher quality of life than in any other places is statistically significant $(t=3.419$, $\mathrm{p}=0.001$ ) after respondents are exposed to the learning content. Nevertheless, the mean difference of place attachment is not statistically significant $(t=-0.418, p=0.677)$ after respondents received the treatment. Result implies that the learning content failed to instil perception of place attachment with regard to the preservation of Luang Prabang world heritage site.

Finally, the mean differences of all three behavioural intention items are statistically significant. The mean difference of behavioural intention is statistically significant $(\mathrm{t}=4.739$, $\mathrm{p}=0.000$ ), implying that the learning content is able to influence respondent's behavioural intention to understand more about the importance of preserving Luang Prabang world heritage site.

\section{DISCUSSION}

\subsection{General Discussion}

There are two points to be emphasized in this study. First, consistent with existing literatures, this study has proven that the PMT-based learning content is highly effective in influencing threat appraisal of negative consequences arise as a result of failure to protect the world heritage site. Threat appraisal attempts to develop fear due to maladaptive behaviours. Threat appraisal in PMT is derived from fear appeal Fear appeal messages have been empirically found to be effective at bringing about behavioural change (Prentice-Dunn \& Rogers, 1986). It is therefore believed that designing fear appeal messages in learning contents aiming to promote world heritage site preservation would also bring about behavioural change among learners.

Second, as oppose to existing literatures, self-efficacy is strongly influenced by the learning content but not response efficacy. According to PMT, both self-efficacy and response efficacy constitute to cope appraisal, which would influence an individual's protection behaviour (Rogers, 1983). Response efficacy refers to the effectiveness of the recommended action in alleviating a threat (Prentice-Dunn \& Rogers, 1986). The learning content developed in this study proposes that understanding the importance of preserving world heritage site, spreading preservation awareness, and following rules and regulations could help to preserve Luang Prabang world heritage site. A possible explanation to the outcome could be attributed that the proposed preservation actions are judged not sufficiently significant to preserve the world heritage site of 
Luang Prabang. Yet, as shown in Table 1, mean value of response efficacy before treatment are 1.8399. Likert scale of less than 3 employed in this study depicts "agreement". Therefore, the absence of statistically significant mean difference of response efficacy could be attributed to the already strong agreement perceived by the respondents even before they were being exposed to the learning content stimulus. Similar explanation could be applied to the outcome of place attachment, which does not exhibit statistically significant mean difference in this study. Nevertheless, Maddux and Rogers (1983) found that coping response plays an important role only when the magnitude of self-efficacy appraisal is low. In addition, behavioural intention to protect was found to be not deteriorated even though low response-efficacy is observed, given high perceived threat and high self-efficacy exist (Maddux \& Rogers, 1983).

\subsection{Implications for Research and Practice}

The findings of this study confirm that learning content designed based on PMT influences threat and coping appraisal of world heritage site preservation. Although PMT has its origin from health protection behaviour, this study extends the scope of PMT applicability to the protection of the invaluable evidences of the past. It is believed that current study introduces new insights in the underexplored topic of promoting world heritage site preservation awareness, which is necessary for long-term survival of the natural and cultural heritage.

This study shows that despite relatively simple design, the PMT-based learning content was able to stimulate respondents' behavioural intention to preserve Luang Prabang world heritage site through understanding the importance of preservation. Hence, heritage site management practitioners could benefit from the outcomes of this study by applying PMT components in the design of communication materials. PMT asserts that behavioural changes could occur as a result of threat appraisal and coping appraisal. Therefore, content that could stimulate threat appraisal and cope appraisal tailored to the needs of local heritage office could be designed to achieve preservation awareness promotion objectives.

\subsection{Limitations and Future Research}

The findings of this study should be interpreted in light of its limitations. Due to resource constraints, current research draws from student sample, which calls for caution on data generalizability. The total 212 valid responses represent approximately $10 \%$ of the student population of the university. In addition, possible sampling bias may contribute to less degree of perception difference. Respondents in this study could have possessed higher level of preservation awareness due to their higher level of education in relation to other residents in the town.

Currently, this study provides strong foundation for further research in the exploration of interaction among threat, coping, and place attachment variables, and the effect of the variables on behavioural intention towards world heritage site preservation. The outcome of theoretical model testing would advance the promotion of world heritage site preservation activities through the lens of human behavioural study.

\section{ACKNOWLEDGEMENTS}

This work was supported by JSPS KAKENHI Grant Number 25303001.

\section{REFERENCES}

Bagozzi, R., \& Moore, D., 1994. Public Service Advertisements: Emotions and Empathy. Journal of Marketing, 58(1), pp. 56-70.

Carter, B., \& Grimwade, G., 1997. Balancing use and preservation in cultural heritage management. International Journal of Heritage Studies, 3(1), pp. 45-53.

Cismaru, M., Cismaru, R., Ono, T., \& Nelson, K., 2011. "Act on Climate Change": An Application of Protection Motivation Theory. Social Marketing Quarterly. 17(3), pp. 62-84.

Cismaru, M., Lavack, A., Hadjistavropoulos, H., \& Dorsch, K., 2008. Understanding health behavior: an integrated model for social marketers. Social Marketing Quarterly, 14(2), pp. 2 - 32.

Floyd, D., Prentice-Dunn, S., \& Rogers, R., 2000. A metaanalysis of research on protection motivation theory. Journal of Applied Social Psychology, 30(2), pp. 407-429.

Hidalgo, M., \& Hernandez, B., 2001. Place attachment: conceptual and empirical questions. Journal of Environmental Psychology, 21(3), pp. 273-281.

Jimura, T., 2011. The impact of world heritage site designation on local communities - A case study of Ogimachi, Shirakawamura, Japan. Tourism Management, 32(2), pp. 288-296.

Maddux, J., \& Rogers, R., 1983. Protection motivation and selfefficacy: A revised theory of fear appeals and attitude change. Journal of Experimental Social Psychology, 19(5), pp. 469-479.

Manzo, L., \& Perkins, D., 2006. Finding common ground: The importance of place attachment to community participation and planning. Journal of Planning Literature, 20(4), pp.335-350.

Markelj, J., 2009. Using protection motivation theory to examine environmental communications: The review of inhome energy saving advertisements. International Journal of Sustainability Communication, 4, pp. 113-124.

Millar, S., 1989. Heritage management for heritage tourism. Tourism Management, 10(1), pp. 9-14.

Nelson, K., Cismaru, M., Cismaru, R., \& Ono, T., 2011. Water management information campaigns and protection motivation theory. International Review on Public and Nonprofit Marketing, 8(2), pp. 163-193.

Poong, Y., Yamaguchi, S., \& Takada, J., 2013. Possibility to use Mobile Learning to promote World Heritage Site Preservation awareness in Luang Prabang, Lao PDR: A readiness study. XXIV International CIPA Symposium, Strasbourg, France, Vol. II-5/W1, pp. 247-252.

Prentice-Dunn, S., \& Rogers, R., 1986. Protection motivation theory and preventive health: Beyond the health belief model. Health Education Research, 1(3), pp. 153-161.

Rogers, R., 1975. A protection motivation theory of fear appeals and attitude change. Journal of Psychology, 91(1), pp. 93 - 114. 
Rogers, R., 1983. Cognitive and physiological processes in fear appeals and attitude change: A revised theory of protection motivation. In J. C. Petty, Social Psychophysiology. Guilford Press, NY, USA.

Ruiter, R., \& Kok, G., 2005. Saying is not (always) doing: Cigarette warning lables are useless. European Journal of Public Health, 15(3), pp. 329.

Shankar, B., \& Swamy, C., 2013. Creating awareness for heritage conservation in the city of Mysore: Issues and policies. International Journal of Modern Engineering Research, 3(2), pp. 698-703.

Small, D., \& Verrochi, N., 2009. The face of need: Facial emotion expression on charity advertisements. Journal of Marketing Research, 46(6), pp. 777-787.

UNESCO, 2008. Reactive Monitoring Mission to the Town of Luang Prabang World Heritage Property Lao People's Democratic Republic. Quebec City, Canada.

Vance, A., Siponen, M., \& Pahnila, S., 2012. Motivating IS security compliance: Insights from habit and protection motivation theory. Information \& Management, 49(3-4), pp. 190-198.

\section{APPENDIX}

Questionnaire items

Severity 1(S1): If Luang Prabang becomes "World Heritage Site in Danger", how severe do you think it is that tourists' visits will be affected?

Severity 2 (S2): If Luang Prabang becomes "World Heritage Site in Danger", how severe do you think it is that local people's economic income will be affected?

Severity 3 (S3): If Luang Prabang becomes "World Heritage Site in Danger", how severe do you think it is that national pride will be affected?

Vulnerability 1 (V1): If people do not follow rules and regulations when building or renovating their houses, how likely do you think it is that Luang Prabang will become "World Heritage Site in Danger"?

Vulnerability 2 (V2): If people cut trees without approval, how likely do you think it is that Luang Prabang will become "World Heritage Site in Danger"?
Vulnerability 3 (V3): If people build or renovate their houses based on own personal likings, how likely do you think it is that the traditional architecture buildings will slowly be lost in the future?

Self-efficacy 1 (SE1): How confident that you can understand the importance of preserving Luang Prabang World Heritage Site?

Self-efficacy 2 (SE2): How confident that you can understand the importance of following World Heritage Site rules and regulations?

Self-efficacy 3 (SE3): How confident that you can help to spread World Heritage Site preservation awareness through Internet technologies (such as Facebook, Line and etc.)?

Response efficacy 1 (RE1): How much do you agree that understanding the importance of preserving Luang Prabang World Heritage Site could help to preserve Luang Prabang world heritage site?

Response efficacy 2 (RE2): How much do you agree that spreading World Heritage Site preservation awareness through Internet technologies (such as Facebook, Line, and etc.) could help to preserve Luang Prabang world heritage site.

Response efficacy 3 (RE3): How much do you agree that following rules and regulations of building renovations and constructions could help to preserve Luang Prabang world heritage site.

Place attach 1 (P1): I have positive feelings towards Luang Prabang

Place attach 2 (P2): I am very attached to Luang Prabang

Place attach 3 (P3): I am related with Luang Prabang

Place attach 4 (P4): Luang Prabang is very special place to me

Place attach 5 (P5): I enjoy living in Luang Prabang more than any other places

Place attach 6 (P6): I get more satisfaction out of living in Luang Prabang than from any other places

Place attach 7 (P7): Living in Luang Prabang has higher quality of life than living in any other places

Intention 1 (B1): In the coming six months, I intend to learn more about the importance of preserving Luang Prabang World Heritage Site

Intention 2 (B2): In the coming six months, I expect to learn more about the importance of preserving Luang Prabang World Heritage Site

Intention 3 (B3): In the coming six months, I expect to learn more about the importance of preserving Luang Prabang World Heritage Site 